\title{
Understanding the role of prior knowledge in a multimedia learning application
}

\author{
Riaza Mohd Rias \\ Universiti Teknologi MARA, Malaysia \\ Halimah Badioze Zaman \\ Universiti Kebangsaan Malaysia, Malaysia
}

\begin{abstract}
This study looked at the effects that individual differences in prior knowledge have on student understanding in learning with multimedia in a computer science subject. Students were identified as having either low or high prior knowledge from a series of questions asked in a survey conducted at the Faculty of Computer and Mathematical Sciences at University Technology MARA, Malaysia. The subject domain chosen for this study is a topic taught to undergraduates in the field of Computer Sciences, in the subject of Operating Systems, i.e., Memory Management Concepts. This study utilizes a multimedia application that is shown to a total of 257 students. Early results from the recall and transfer tests indicate that students' individual differences play a vital role in learning outcome. As expected, the low prior knowledge group scored significantly in the recall tests as compared to the transfer test, and the high prior knowledge group performed comparatively better in the transfer test. This suggests that educational designers who wish to foster learning and understanding should incorporate learners' prior knowledge as a design principle.
\end{abstract}

\section{Introduction}

Learning with computer-generated visualizations has become a topic of major interest in recent years. According to Mayer (2001, 2009), multimedia learning is learning from words and pictures and multimedia instructional message, multimedia instructional presentation, or multimedia instruction, is presentation involving words and pictures that is intended to foster learning. Moreover, display design and multimedia contribute significantly to learner performance (Austin, 2009; Rias \& Zaman, 2009, 2011).

Prior knowledge is as important as the learning ability. However, students may have greater prior knowledge, experience and intensive interest, yet have only average learning ability. Using prior knowledge in instructional methods seems to be helpful for students with limited knowledge (Pacheco, Henriques, Almeida, \& Mendes, 2008). One of the most persistent findings in the literature of adult learning is that prior knowledge acts both as a filter and as a cognitive peg; restricting and facilitating the acquisition of new knowledge. What one already knows about a topic and one's perspective regarding that topic influences what is remembered (Mayer, Dow, \& Mayer., 2003). Prior knowledge has been considered the most important single factor that influences learning. Jonassen and Grabowski (1993) defined prior knowledge and achievement as the knowledge, skills or abilities that the learners brings to the learning environment before the instruction. Hannafin (1997) suggested that compared to individuals who have lower prior knowledge, individuals who have higher prior knowledge can quickly determine their needs, generate their own learning strategies, and assimilate new information to their existing knowledge structure. Reiber (1990) also stated that related prior knowledge provides learners with unique relevant elaboration that is unavailable to learners with limited prior knowledge. It is suggested that knowledge will be encoded more meaningfully and retrieved more easily by learners with high prior knowledge. According to Kalyuga, Chandler, and Sweller (2004) the level of learners' prior knowledge or experience could affect the effectiveness of an instructional technique. It could be predicted that students understanding of a topic in multimedia application could depend on levels of learners' prior knowledge, thus, the motivation for this study. To investigate further, this study will look at the effects of low prior knowledge students and high prior knowledge students on both recall and knowledge transfer for a subject taught to undergraduates in the field of information technology and computer sciences.

The subject taught in this multimedia presentation is a topic from operating systems, memory management. Operating Systems (OS) is an important course in many Computer Science, Information Science and Computer Engineering curricula. Some of its topics require a careful and detailed explanation 
from the lecturer as they often involve theoretical concepts and somewhat complex calculations, demanding a certain degree of abstraction from the students if they are to gain full understanding (Park \& Gittleman, 1992; Maia, Machado, \& Pacheco, 2005).

\section{The effects of prior knowledge}

Prior knowledge has a marked effect on learning outcomes (Shapiro, 2004). Mayer and Anderson (1992) found that learning significantly improved for students who possess low prior knowledge when verbal and visual information are presented simultaneously. They suggested that experienced students might be able to build referential connections between verbal and visual information and their existing knowledge on their own. A theoretical rationale argued by Mayer (2001), is that high-knowledge learners are able to use their prior knowledge to compensate for lack of guidance in the presentation - such as by forming appropriate mental images from words - whereas low-knowledge learners are less able to engage in useful cognitive processing when the presentation lacks guidance.

In a study looking into prior knowledge as a subject variable that changes outcomes of learning, Shapiro (2004) strongly suggests a relationship between prior knowledge and learning outcome. McNamara, Kintsch, Songer, and Kintsch (1996), used high-school biology content, in which additional explanatory text was found to benefit only low prior knowledge students. High prior knowledge learners benefited more from minimally coherent instructional materials. McNamara, Kintsch, Songer, and Kintsch (1996) suggested that this effect could be a function of more active processing required by the high prior knowledge learner. Kalyuga, Chandler, and Sweller (1998) suggested that the redundancy effect might be a reasonable alternative explanation for these results.

In a different study examining instructional strategy, visualisation, locus of control and prior knowledge (Akanbi \& Dwyer, 1989), 206 university students were exposed to a 2000 word unit describing the human heart and its processes. The instructional strategies under study were inductive (discovery / low disciplined) or deductive (didactic / high disciplined). Visualisation supports were considered supplementary for this study, and the treatment conditions were the presence or absence of visualisations in the instructional materials. Students with internal locus of control were expected to benefit more from inductive learning strategies. High prior knowledge learners were expected to perform better than medium and low prior knowledge learners. Results of the study found that high prior knowledge learners performed better regardless of instructional strategy, and that the presence of visualisation reduced differences in performance of medium and low prior knowledge learners in a test of comprehension.

In a study conducted by Owens and Dwyer (2005), 180 students identified as having high or low prior knowledge were randomly assigned to one of three groups: (a) animation (control); (b) animation with attention-directing strategies; and (c) animation with visual-elaborating strategies. Significant differences in achievement were realized on the criterion measures between students identified as possessing high and low levels of prior knowledge. Based on the literature, the expectation was that low prior knowledge students would benefit from the additional cueing because they were given more stimuli through visualisation and, thus, would perform as well on the criterion tests as high prior knowledge students. The study (Owens \& Dwyer, 2005) contradicts this research. The low prior knowledge students performed contrary to the research literature. The data analysis showed that the scores decreased from treatments (a) to (c). A major difference between high and low prior knowledge students is that the high prior knowledge students possess knowledge structures which contain a larger number of knowledge units and the structures are better organized. When supporting knowledge exists, learners gain the capacity to compare and contrast to-be-learned instruction within existing knowledge, providing uniquely relevant and elaborate knowledge unavailable to learners with limited prior knowledge. Consequently, lessons or knowledge generally will be encoded more meaningfully and retrieved more successfully by learners with high versus low prior knowledge (Rieber, 2004). In another similar study, Zhu and Grabowski (2004) investigated the instructional effects of various animation strategies in facilitating the achievement of students on tests measuring different educational objectives (drawing, identification, terminology and comprehension). Three treatment groups were involved and included static graphic, animation used as an attention-gaining strategy, and animation used as an attention-gaining and elaboration strategy. The findings of this study showed that students with lower prior knowledge performed equally well to those with high prior knowledge in all three treatments. This result was contrary to much previous research that showed high prior knowledge students performing better than low prior knowledge students regardless of 
treatment. This factor could probably be explained by dual coding theory. Students with low prior knowledge are helped more when verbal and visual information is presented simultaneously since it helps them build referential connections (Mayer \& Anderson, 1992). There was a significant difference between the high and low prior knowledge participants in the pretest, but the differences were reduced to insignificant differences in the four achievement tests after they went through the treatments (Zhu \& Grabowski, 2004).

In research on constructing mental models (Schnotz \& Bannert, 2003), low and high prior knowledge were the indicators used to measure learning from verbal and pictorial representations. Learners with low knowledge benefit from pictures in a text, whereas learners with higher prior knowledge seemed to be able to construct a mental model of the described content only from the text (Mayer, 1997). This research result suggests that pictures facilitate learning only if individuals have low prior knowledge and if the subject matter is visualised in a task-appropriate way. Schnotz and Bannert (2003) suggest that good graphic design is important for individuals with low prior knowledge who need pictorial support in constructing mental models. Well-designed pictures are also important for individuals with high prior knowledge because these individuals can be hindered in their mental model construction through inappropriate forms of visualisation.

Many researchers use prior knowledge as an important factor in determining the students' achievement level. The use of prior knowledge has appeared in a variety of subjects such as mathematics, science, language and even computer science. Results have not been consistent and have varied according to different domains. Researchers have agreed on this and proposed that more research be conducted on in the area of prior knowledge.

\section{Assessment of multimedia learning}

In terms of learning and deeper understanding, a comprehensive assessment is needed. Previous research focused on transfer and retention (recall) learning (Mayer, 2001, 2009). Noting that retention is an important aspect of learning, where the learner is able to remember what was presented in the multimedia treatment, Mayer's cognitive theory of multimedia learning (CTML) contends that deeper learning occurs when students can transfer the concepts and processes to novel situations, and can demonstrate understanding by inference and induction. The theory of multimedia learning focused on a demonstration of various design principles, with transfer and recall performances measured by short assessments following a scientific, process-oriented learning module.

\section{Method}

\section{Participants}

A total of 257 students participated in this study. All students were from the Faculty of Computer and Mathematical Sciences at UiTM, Malaysia (173 females and 84 males). There was an uneven number in terms of gender due to the current situation at Malaysian universities where the female population far exceeds the male population. The age of the participants is around 20-24 years old.

\section{Materials and procedure}

The multimedia system was developed using Macromedia Flash MX $2004^{\mathrm{TM}}$. The instructional design is self-paced and content was closely aligned with the textbook (Silberschatz, Galvin, \& Gagne, 2009) used by instructors teaching this subject. All the participants had to take a prior knowledge survey before sitting for the treatment. The prior knowledge survey was conducted in a classroom setting in two different sessions of 20 minutes. This is to determine if the students had high or low prior knowledge. A similar methodology was used by Moreno (2004) to conduct research on cognitive load and student understanding. Some of the questions in the survey asked if students had taken the subject of operating systems (OS) prior to this survey; (some first year students had already taken an introductory course in OS in their Diploma). Also some basic questions on memory management were asked and students were supposed to tick in the available boxes if they were familiar with certain terms. After completing the prior knowledge survey, students were divided into two groups, which was low prior knowledge and high prior knowledge. The low prior knowledge group consisted of students who scored less than $50 \%$ in the prior 
knowledge survey and high prior knowledge group scored greater than 50\%. A total of 120 students from that pool of students were identified as low prior knowledge and 137 students were in the high prior knowledge category. An initial investigation indicated that students who were categorized in the high prior knowledge category were undergraduate students who had completed their diploma in computer science and were continuing their degree with some transfer credits; whereas, the low prior knowledge students were foundation students in their first semester.

\section{The experiment}

Experimental sessions were conducted at different times. This is because the experiment was conducted during the semester where students' class schedules were full and there was a limited number of labs in the faculty to conduct the experiments at the same time. The multimedia-based instruction gave an explanation of memory management concepts, as part of the syllabus in operating systems, which consisted of background on memory management, swapping technique, contiguous allocation technique and paging technique. Then the students were asked to view the multimedia instruction, which was installed on each computer in the computer lab. The animation was self-paced and interactive. Students could view the animation with the play button and they could rewind, pause or stop according to their needs (see Figures 4 and 5 to view samples of the interactive multimedia instructions). After the treatment, each participant had to take a post-test. The system with animation and text had animation designed using Macromedia Flash and the computer concepts of swapping, contiguous memory allocation and paging techniques were explained using animation. All students were given two hours to view the multimedia learning system and then they were asked to answer the recall and transfer questions.

\section{Post-test}

A multiple-choice, paper-based test was given to all participants who viewed the multimedia treatment. This test procedure followed the conventional paradigm used to evaluate the mental model constructed during multimedia learning (Mayer \& Anderson, 1992). All the course materials and test questions were validated by the subject matter experts from the Faculty of Computer and Mathematical Sciences, UiTM, Shah Alam. The tests were divided into two parts, the recall test and transfer test. The recall test asked questions which required students to recall or remember some basic facts mentioned in the slides. Figure 1 shows a sample of a recall type test question.

When a process arrives in a contiguous allocation and needs memory, we search for a large enough for this process. If we find one, we allocated only as much memory as needed and then compete for the CPU.

$\begin{array}{ll}\text { a) } & \text { Driver } \\ \text { b) } & \text { Partition } \\ \text { c) } & \text { Address } \\ \text { d) } & \text { Page }\end{array}$

Figure 1. Sample of recall test question.

The transfer test required students to solve some problems based on the knowledge learned in the multimedia system. Figure 2 shows a sample of a transfer test question.

Calculate the physical address for the logical address of:

$$
(1,0)
$$
a) 32
b) $\quad 27$
c) 35
d) 22

Figure 2. Sample of transfer test question. 
The recall test had some fill-in-the-blanks and multiple-choice questions whereas, the transfer test had only multiple-choice questions. The transfer test required the students to really understand the calculation method and formula to solve the problem stated.

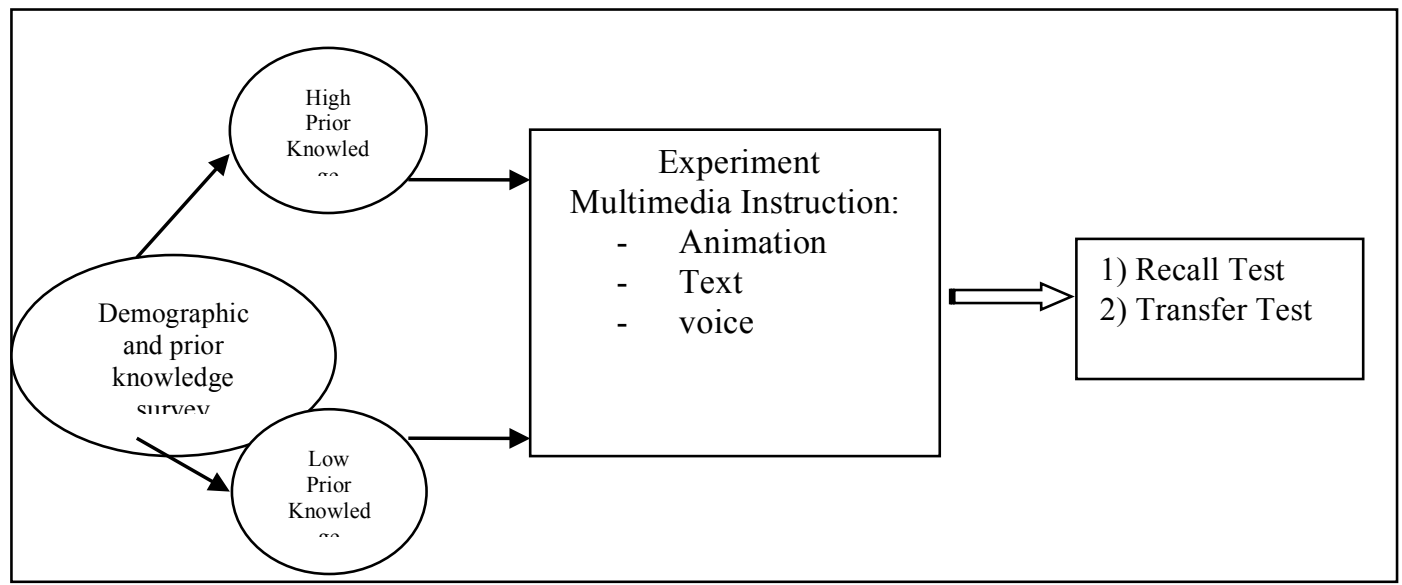

Figure 3. Graphical representation of the research design.

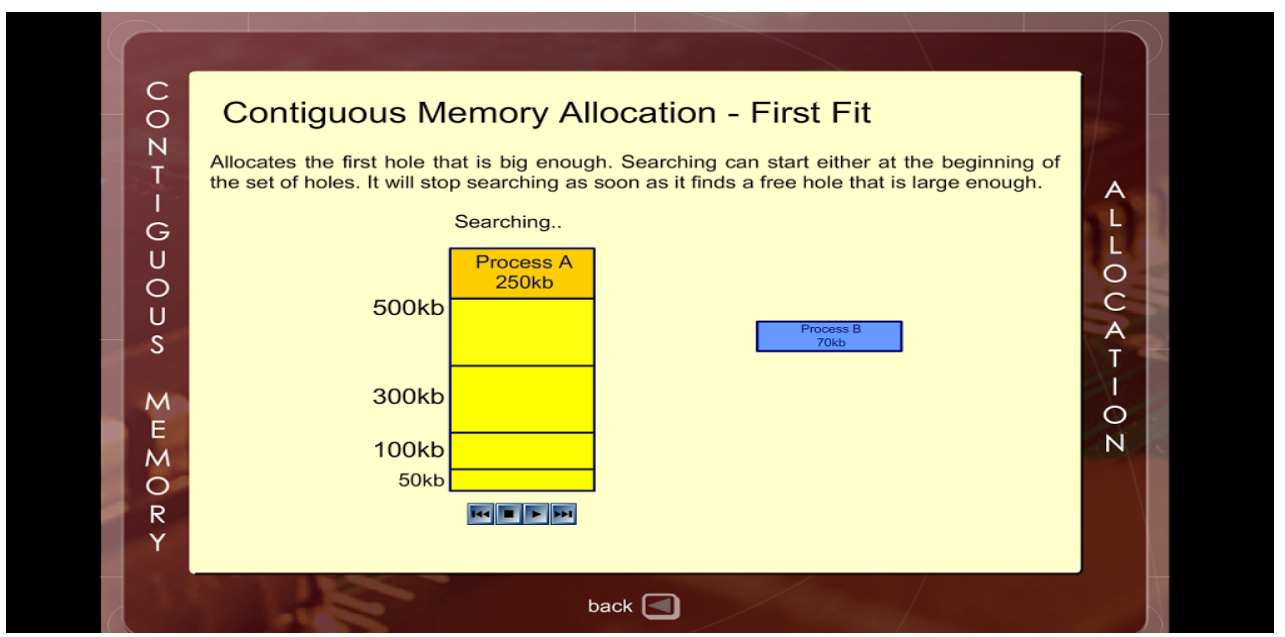

Figure 4. Contiguous memory allocation screen.

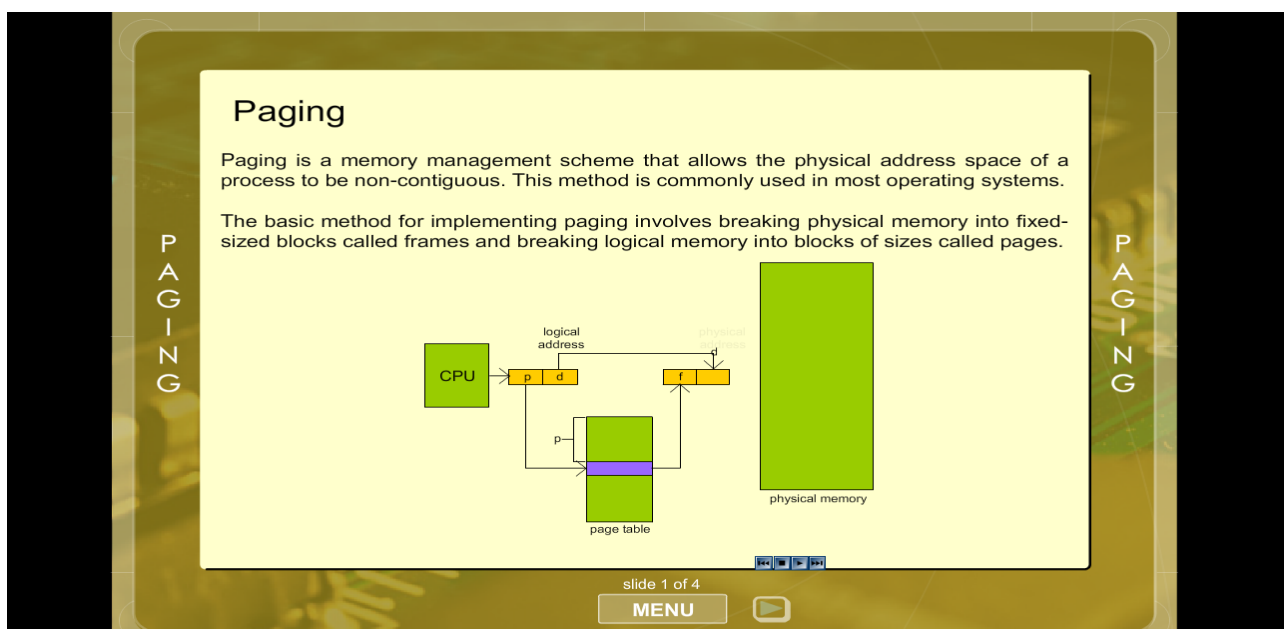

Figure 5. Paging screen. 


\section{Results}

\section{Effects from recall and transfer scores}

The importance of low and high prior knowledge is based on the individual differences principle in Mayer's cognitive theory of multimedia learning. This principle states that design effects are stronger for low-knowledge learners than for high-knowledge learners. Since the test scores are normally distributed and variance is constant, a t-test is therefore conducted. Below is the hypothesis and results for this investigation.

Hypotheses 1: There is a significant difference for low prior knowledge students and high prior knowledge students on the recall score test $(\%)$. $\left(\mathrm{H}_{0}: \mu_{\text {Low }}=\mu_{\mathrm{High}} \quad\right.$ vs. $\left.\mathrm{H}_{1}: \mu_{\text {Low }} \neq \mu_{\mathrm{High}}\right)$

Table 1

Independent sample t-test on the recall score test

\begin{tabular}{lccccc}
\hline Student & Mean & Std. Deviation & $N$ & $t$ & $p$ \\
\hline Low prior knowledge & 64.33 & 18.55 & 120 & 6.25 & $<0.001$ \\
High prior knowledge & 50.00 & 18.17 & 137 & & \\
\hline
\end{tabular}

Based on Table 1, the results indicate that there was a significant difference between low prior knowledge and high prior knowledge students on the recall score tests $p=0.000$. But in this result, students who had a low prior knowledge on operating systems got a higher mean score $(64.3 \%)$ as compared to the students with high prior knowledge $(50.0 \%)$ on the recall score test.

Hypotheses 2: There is a significant difference for low prior knowledge students and high prior knowledge students on the transfer score test (\%). $\left(H_{0}: \mu_{\text {Low }}=\mu_{\text {High }} \quad\right.$ vs. $H_{1}: \mu_{\text {Low }} \neq \mu_{\text {High }}$ )

Table 2

Independent sample t-test on the transfer score test

\begin{tabular}{lccccc}
\hline Students & Mean & Std. Deviation & $N$ & $t$ & $p$ \\
\hline Low prior knowledge & 34.64 & 18.02 & 120 & -13.13 & $<0.001$ \\
High prior knowledge & 60.40 & 13.31 & 137 & & \\
\hline
\end{tabular}

Based on the independent sample $t$-test result, there was a difference between low prior knowledge and high prior knowledge students on the transfer score tests since $p<0.05$. The high prior knowledge students got higher score $(60.4 \%)$ as compared to the low prior knowledge students $(34.6 \%)$ on the transfer score. This result corresponds to what was expected of this research. Both the hypotheses were accepted.

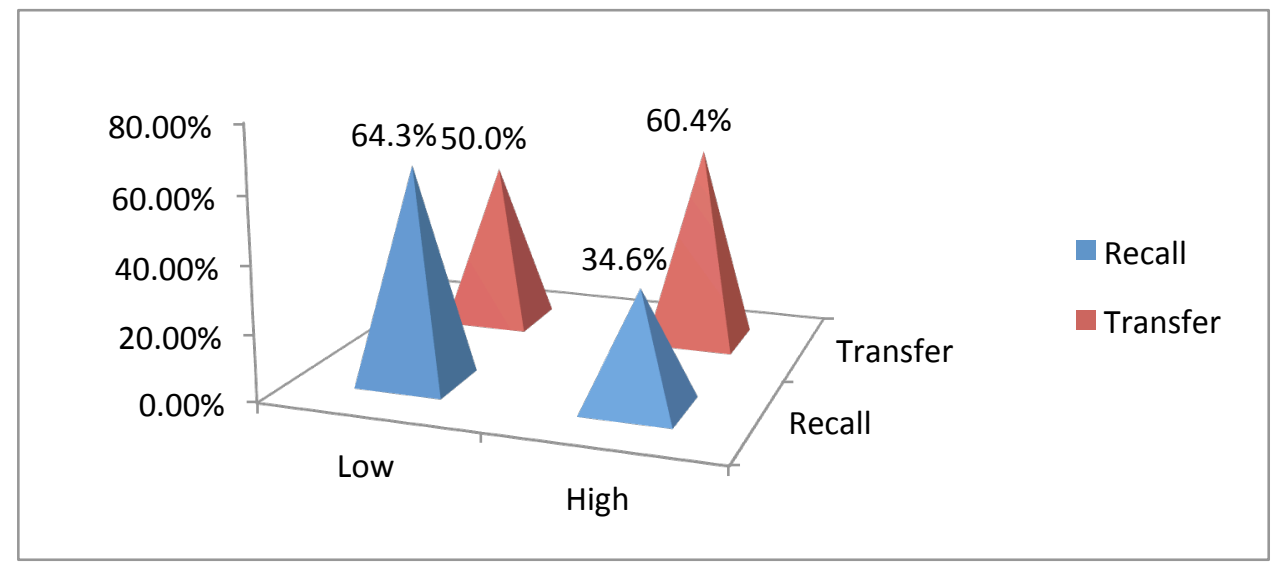

Figure 6. Mean score of recall and transfer tests for low and high prior knowledge students. 


\section{Effects from prior knowledge}

Hypotheses 3: There is a significant difference on student recall scores and transfer scores for low prior knowledge students. $\left(\mathrm{H}_{0}: \mu_{\text {Recall }}=\mu_{\text {Transfer }}\right.$ vs. $\left.\mathrm{H}_{1}: \mu_{\text {Recall }} \neq \mu_{\text {Transfer }}\right)$

Table 3

Paired sample t-test on the score test for low prior knowledge students

\begin{tabular}{lccccc}
\hline Test & Mean & Std. Deviation & $N$ & $t$ & $p$ \\
\hline Recall knowledge scores & 64.33 & 18.55 & 120 & 13.42 & $<0.001$ \\
Transfer knowledge scores & 34.64 & 18.02 & 120 & & \\
\hline
\end{tabular}

A paired samples $t$-test was used to compare the recall and transfer score tests on low and high prior knowledge students. A paired sample $t$-test compares the means of two variables. It computes the difference between the two variables for each case, and tests to see if the average difference is significantly different from zero (Montgomery, 2001).

Based on the paired $t$-test result that can be observed in Table 3, there exists a difference between recall knowledge scores and transfer knowledge scores for low prior knowledge students since the $p$-value $=$ 0.000 . Students who had low prior knowledge on operating systems got a higher score on recall knowledge questions $(64.3 \%)$ as compared to those students who answered the transfer knowledge questions $(34.6 \%)$.

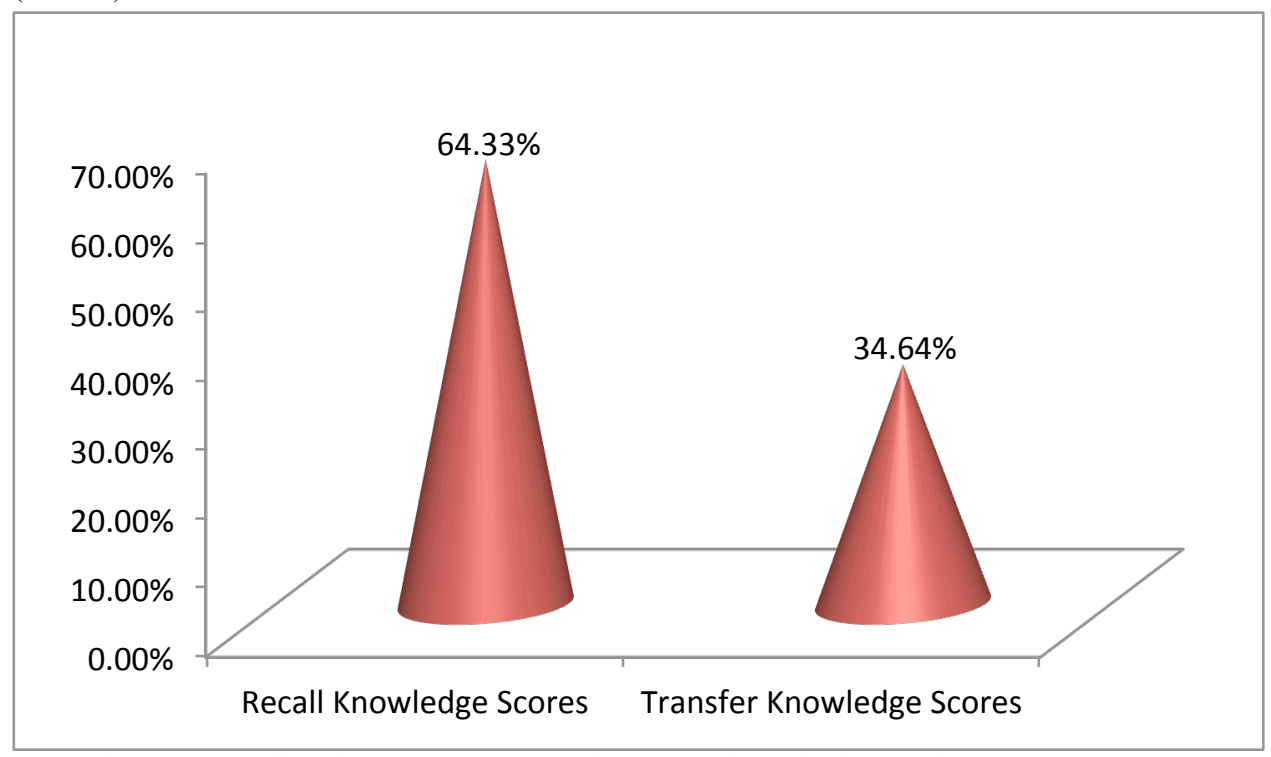

Figure 7. Cone chart on recall and transfer tests for low prior knowledge students.

Hypotheses $_{4}:$ There is a significant difference on student recall scores and transfer scores for high prior knowledge students. $\left(H_{0}: \mu_{\text {Recall }}=\mu_{\text {Transfer }} \quad\right.$ vs. $\left.\quad H_{1}: \mu_{\text {Recall }} \neq \mu_{\text {Transfer }}\right)$

Table 4

Paired sample t-test on the score test for high prior knowledge students

\begin{tabular}{lccccc}
\hline Test & Mean & Std. Deviation & $N$ & $t$ & $p$ \\
\hline Recall knowledge scores & 74.96 & 15.86 & 137 & 13.14 & $<0.001$ \\
Transfer knowledge scores & 50.00 & 18.17 & 137 & & \\
\hline
\end{tabular}

Based on the paired t-test result in Table 4, there was a difference on recall knowledge scores and transfer knowledge scores for high prior knowledge students since the $p$-value $=0.000$. Students who had a high prior knowledge on operating systems got a higher score on recall knowledge questions $(75.0 \%)$ as 
compared to students who attempted the transfer knowledge questions $(50.0 \%)$. The hypotheses were accepted.

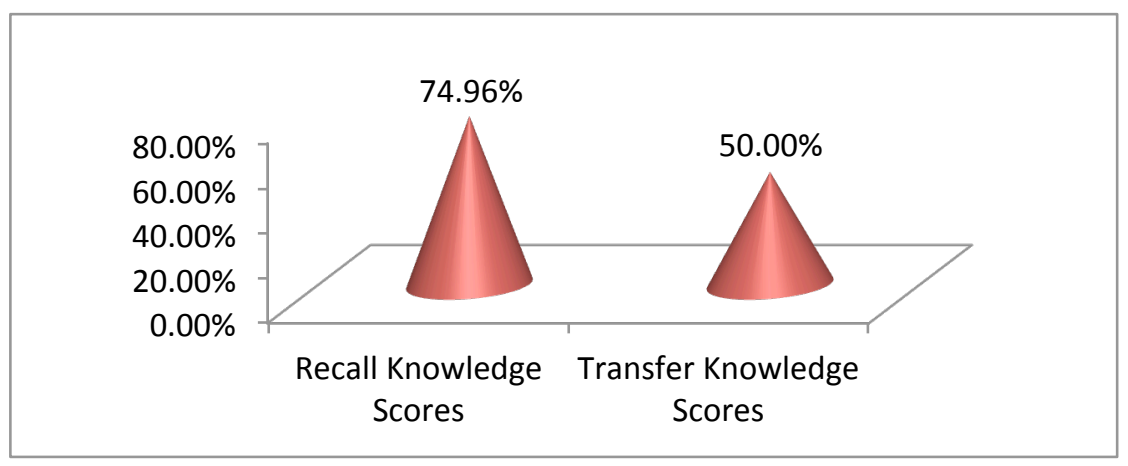

Figure 8. Cone chart on recall and transfer tests for high prior knowledge students.

\section{Students' reaction to treatment}

After viewing the system, 10 students from the two groups which consist of 5 low prior knowledge students and 5 high prior knowledge students were asked about the multimedia software that they had viewed. When asked which topic was the most challenging or the most difficult to understand, most students, especially from the low prior knowledge category had replied "Paging". Students had to spend more time learning the Paging section compared to the other sub-topics.

Students felt that the treatment was a good aid for learning. They found it motivating and useful, especially when understanding the concepts in memory management. Students especially enjoyed viewing the animation. The low prior knowledge students who had never learnt this topic felt that they could understand most of the concepts easily, except Paging, which took them more time to understand. The high prior knowledge students felt that the system was very useful and helped them recall what they had learnt previously in the Diploma level. When asked if the system could replace a traditional lecture in the classroom, all the students disagreed that the system should replace the lecturer. They felt that a lecturer is still needed to explain the topic in more detail.

Students agreed that the questions asked in the tests were relevant to the multimedia treatment. Nevertheless, some students felt that they needed more examples in the system to actually understand the calculation part in Paging. The two examples shown were not enough.

\section{Discussion}

The research investigated whether students' prior knowledge affects the post-test outcome of students who entered the undergraduate degree program at UiTM from either Matriculation or Diploma programs. The findings of this research could be useful for both educators and learners to know if high and low prior knowledge of learners have any significant effect in learning outcome using different modes of instructions. Findings of this study indicated that there was a difference for students with low and high prior knowledge on the recall score tests. Results showed that students who had low prior knowledge on operating systems obtained a higher mean score, compared to students with high prior knowledge. As for the transfer score test, there was a difference for students with low and high prior knowledge. Students with high prior knowledge obtained a higher score compared to students with low prior knowledge.

When a paired $t$-test was conducted to compare results of students in the low prior knowledge category only, there was a significant difference for recall knowledge scores and transfer knowledge scores. Students with low prior knowledge on operating systems obtained a higher score on recall knowledge questions compared to students with low prior knowledge who answered the transfer knowledge questions. Finally, when a paired t-test was conducted to compare results of students with high prior knowledge category only, there was a significant difference for recall knowledge scores and transfer knowledge scores. Students with high prior knowledge on operating systems obtained a higher score on 
recall knowledge questions compared to students with high prior knowledge who answered the transfer knowledge questions.

Based on the literature investigated, design effects are stronger for students with low prior knowledge than for students with high prior knowledge (Mayer, 2001). Mayer also stated that the theoretical rationale for this effect is due to the fact that learners with high knowledge are able to use their prior knowledge to compensate for lack of guidance in the presentation (such as forming appropriate mental images from words), whilst learners with low prior knowledge are less able to engage in useful cognitive processing when the presentation lacks guidance. When well-designed instruction is presented, high and low knowledge learners will both be able to understand the presentation. In this scenario, low knowledge learners would benefit most from the implementation of good design principles. Furthermore, according to Renkl (2002), worked examples that require students to self explain may prove beneficial to students with high domain knowledge because the worked examples provide additional or corrective information that may allow students to build on to their schema. This explains why in this current research, students with high prior knowledge scored better in the transfer tests.

In order to obtain a deeper insight to the results on recall and transfer tests of the students from both low and high knowledge category, another two hypotheses were developed (Hypotheses $3 \& 4$ ). The findings showed that there was a significant difference in recall and transfer knowledge scores for students with low prior knowledge. Students with low prior knowledge on operating systems obtained a higher score on recall knowledge questions compared to students who answered the transfer knowledge questions. According to Schnotz and Bannert (2003), graphics facilitate learning only if individuals have low prior knowledge and if the subject matter is visualized in a task-appropriate manner. Good graphic design is beneficial for individuals with low prior knowledge who need pictorial support in constructing mental models. However, it is also beneficial for individuals with high prior knowledge. This is inappropriate because forms of visualization can hinder their mental model construction (Schnotz \& Bannert, 2003).

Findings on students with high prior knowledge also indicated that there was a significant difference for recall and transfer knowledge scores. Students with high prior knowledge on operating systems obtained a higher score on recall knowledge questions compared to those who did the transfer knowledge questions. Students with high prior knowledge had learned the subject of operating systems and thus, had an added advantage compared to students with low prior knowledge. Owens and Dwyer (2005) in their study showed that students with high prior knowledge have developed a knowledge structure that is better organized with a larger number of knowledge units. When supporting knowledge exists, learners gain the capacity to compare and contrast to-be-learned instruction within existing knowledge, providing uniquely relevant elaboration unavailable to learners with limited prior knowledge. Consequently, lesson knowledge generally will be encoded more meaningfully and retrieved more successfully by learners with high versus low prior knowledge (Rieber, 1990).

Basically, both learners with low and high prior knowledge performed better in recall compared to transfer questions. However, after examining the results, students with high prior knowledge performed better in the transfer questions compared to students with low prior knowledge, even though the total scores were not significant. The transfer questions required students to think and apply what they knew to solve problems. Some mathematical questions were asked which required them to use some formulae. As expected, students with low prior knowledge did not perform well in the transfer knowledge questions. Serafino (1998) found that students with high prior knowledge often performed better with complex problem-solving questions. This is because transfer is described as the ability of students to apply prior knowledge to a setting, which is sufficiently novel to indicate that new learning is required (Serafino, 1998). Based on this research, the results obtained showed that some interaction had occurred between prior knowledge of students and instructions learned to produce some effective transfer of knowledge.

It was expected that the students with high prior knowledge would perform better than students with low prior knowledge in each treatment. The plausible reason for this is that the animations and graphics were able to attract the students' attention to the animation itself instead of the instructional content. The repeated movement of the animation in the form of boxes in the paging and contiguous memory allocation segments plausibly had bored the students. Moreover, students were not motivated enough to participate in the study since their performance would not affect their course grades. The results obtained for this section did not come as a surprise. Students with low prior knowledge scored higher marks in the 
recall test compared to the students with high prior knowledge. This finding concurs with previous the literature on this aspect (Mayer, 2001; Mayer \& Moreno 2003; Moreno, Mayer, Spires, \& Lester, 2001).

\section{Conclusion}

The research investigated whether students' prior knowledge affects the post-test outcome of students who entered the undergraduate degree program at UiTM from either Matriculation or Diploma programs. Findings of this research are useful for educators and learners to gauge the influence of a multimedia application on high and low prior knowledge learners on learning. This experience has developed a better understanding of the relationship between student experience levels and instructional design methods as suggested by Sweller (1999) and Rias \& Zaman (2009).

\section{Acknowledgements}

The authors would like to thank the Research Management Institute at University Technology MARA and the Institute of Visual Informatics at Universiti Kebangsaan Malaysia for supporting this research.

\section{References}

Austin, K. A. (2009). Multimedia learning: Cognitive individual differences and display design techniques predict transfer learning with multimedia learning modules. Computers \& Education, 53, 1339-1354.

Akanbi, M. R., \& Dwyer, F. M. (1989). Effects of students' prior knowledge level on their ability to profit from visualized inductive and deductive instructional strategies. International Journal of Instructional Media, 16, 69-77.

Hannafin, M. J. (1997). The case for grounded learning systems design: what the literature suggests about effective teaching, learning, and technology. Proceedings of the Australian Society for Computers in Learning in Tertiary Education (ASCILITE), Retrieved from http://www.ascilite.org.au/conferences/perth97/papers/Hannafink/Hannafink.html

Jonassen, D., \& Grabowski, B. (1993). Handbook of individual differences, learning, and instruction. Mahwah, NJ: Lawrence Erlbaum Associates.

Kalyuga, S., Chandler, P., \& Sweller, J. (2004). When redundant on-screen text in multimedia technical instruction can interfere with learning. Human Factors, 46(3), 67-581.

Kalyuga, S., Chandler, P., \& Sweller, J. (1998). Levels of expertise and instructional design. Human Factors, 40, 1-17.

Maia, L. P., Machado, F. B., \& Pacheco, A. C. Jr. (2005, June). A constructivist framework for operating systems education: A pedagogical using the SOsim. Paper presented at ITiCSE '05, Monte de Caparica, Portugal.

Mayer, R. E. (1997). Multimedia learning: Are we asking the right questions? Educational Psychologist, 32(1), 1-19.

Mayer, R.E. (2001). Multimedia learning. Cambridge: Cambridge University Press.

Mayer, R. E. (2009). Multimedia learning (2nd ed.). Cambridge: Cambridge University Press.

Mayer, R. E., \& Anderson, R. B. (1992). The instructive animation: Helping students build connections between words and pictures in multimedia learning. Journal of Educational Psychology, 84(4), 444452. 
Mayer, R. E., Dow, G. T., \& Mayer, S. (2003). Multimedia learning in an interactive self-explaining environment: What works in the design of agent-based microworlds. Journal of Educational Psychology, 95(4), 806-812.

Mayer, R. E., \& Moreno, R. (2003). Nine ways to reduce cognitive load in multimedia learning. Educational Psychologist, 38(1), 43-52.

McNamara, D. S., Kintsch, E., Songer, N. B., \& Kintsch, W. (1996). Are good texts always better? Interactions of text coherence, background knowledge, and levels of understanding in learning from text. Cognition and Instruction, 14(1), 1-43.

Montgomery, D. C. (2001). Design and analysis of experiments. Arizona State University: John Wiley.

Moreno, R., Mayer, R. E., Spires, H.A., \& Lester, J.C. (2001). The case for social agency in computerbased teaching: do students learn more deeply when they interact with animated pedagogical agents? Cognition and Instruction, 19(2), 177-213.

Moreno, R. (2004). Decreasing cognitive load for novice students: Effects of explanatory versus corrective feedback on discovery-based multimedia. Instructional Science, 32, 99-113.

Owens, R., \& Dwyer, F. (2005). The effect of varied cueing strategies in complementing animated visual imagery in facilitating achievement of different educational objectives. International Journal of Instructional Media, 32(4), 373-384.

Pacheco, A., Henriques, J., Almeida, A. M., \& Mendes, A. J. (2008). Mathematics and programming: Some studies. Proceeding of the International Conference on Computer Systems and Technologies and Workshop for PhD Students in Computing. doi:10.1145/1500879.1500963

Park, O., \& Gittleman, S. S. (1992). Selective use of animation and feedback in computer-based instruction. Educational Technology Research and Development, 40(4), 27-38.

Renkl, A. (2002). Worked-out examples: instructional explanations support learning by self-explanations. Learning and Instruction, 12(5), 529-556.

Rias, R. P. M., \& Zaman, H. B. (2009). Using 3-D animation in multimedia learning for memory management concepts. Proceedings of the 2009 International Conference on Signal Processing Systems, Singapore, 748-753.

Rias, R. M., \& Zaman, H. B. (2011). Different visualization types in multimedia learning: A comparative study. In H. B. Zaman, P. Robinson, M. Petrou, P. Olivier, T. K. Shih, S. Velastin, \& I. Nyström (Eds.), Lecture Notes in Computer Science: Vol 7067. Visual Informatics: Sustaining Research and Innovations (pp. 408-418).

Rieber, L. P. (1990). Animation in computer-based instruction. Educational Technology Research and Development, 38(1), 77-86.

Rieber, L. P. (2004). Microworlds. In D. Jonassen (Ed.), Handbook of research for educational communications and technology (2nd ed.). Mahwah, NJ: Lawrence Erlbaum Associates.

Schnotz, W., \& Bannert, M. (2003). Construction and interference in learning from multiple representation. Learning and Instruction, 13, 141-156.

Serafino, K. C. (1998). Prior knowledge and anchored instruction on students' complex mathematical problem solving and transfer. (Unpublished doctoral dissertation). Fordham University.

Shapiro, A. (2004). How including prior knowledge as a subject variable may change outcomes of learning research. American Educational Research Journal, 41(1), 159-189. 
Silberschatz, A., Galvin, P. B., \& Gagne, G. (2009). Operating system concepts (7th ed.). NJ: John Wiley $\&$ Sons.

Sweller, J. (1999). Instructional design in technical areas. Camberwell, Victoria: ACER Press.

Zhu, L., \& Grabowski, B. (2004, October). The effects of various animation strategies in facilitating the achievement of students on tests measuring different educational objectives. Paper presented at the Association for Educational Communications and Technology, Chicago, IL.

Corresponding author: Riaza Mohd Rias, riaza@tmsk.uitm.edu.my

Australasian Journal of Educational Technology (C) 2013.

Please cite as: Rias, R. M., \& Zaman, H. B. (2013). Understanding the role of prior knowledge in a multimedia learning application. Australasian Journal of Educational Technology, 29(4), 537-548. 